\title{
Physical activity patterns in third trimester of pregnancy - use of pregnancy physical activity questionnaire in Poland
}

\author{
Cezary Wojtyła ${ }^{1,2, A-F} \oplus$, Michał Ciebiera ${ }^{3, B-F} \oplus$, Paulina Wojtyła-Buciora ${ }^{4,5, A, D-F} \oplus$, \\ Anna Janaszczyk ${ }^{4, C-D, F \oplus}$, Paulina Brzęcka ${ }^{4, B, D, F}$, Andrzej Wojtyła ${ }^{4, B-F} \oplus$ \\ ${ }^{1}$ European Observatory of Health Inequalities, State University of Applied Sciences, Kalisz, Poland \\ ${ }^{2}$ Department of Oncological Gynecology and Obstetrics, Centre of Postgraduate Medical Education, Warsaw, Poland \\ ${ }^{3}$ Second Department of Obstetrics and Gynecology, Center of Postgraduate Medical Education, Warsaw, Poland \\ ${ }^{4}$ Faculty of Medicine, State University of Applied Sciences, Kalisz, Poland \\ ${ }^{5}$ Department of Physiolgy, University of Medical Sciences, Poznan, Poland \\ A - Research concept and design, B - Collection and/or assembly of data, C - Data analysis and interpretation, \\ $D$ - Writing the article, $E$ - Critical revision of the article, $F$ - Final approval of article
}

Wojtyła C, Ciebiera M, Wojtyła-Buciora P, Janaszczyk A, Brzęcka P, Wojtyła A. Physical activity patterns in third trimester of pregnancy - use of pregnancy physical activity questionnaire in Poland. Ann Agric Environ Med. 2020; 27(3): 388-393. doi: 10.26444/aaem/110480

\begin{abstract}
I Abstract
Introduction. Adverse pregnancy outcomes are less common among physically active women, and children born to such mothers are less likely to be at risk for macrosomia, obesity and metabolic diseases in the future.

Objectives. The aims of the study were to establish physical activity (PA) patterns among pregnant women in the third trimester, and to determine the attitudes of prenatal care providers to maternal PA during pregnancy.

Materials and method. The study was conducted in 2017 using surveys from the Polish Pregnancy-related Assessment Monitoring System program (Pol-PrAMS). The study included 3,451 postpartum women. The Pregnancy Physical Activity Questionnaire was used to investigate their PA. This part of Pol-PrAMS study was completed by 2,744 postpartum women who were subjected to statistical analysis.

Results. Sedentary or light physical activity comprised $75 \%$ of the overall PA in the third trimester of pregnancy (mean values of energy expenditure: 67 and $93.3 \mathrm{MET}$-h/week, respectively). Household or caregiving activities accounted for almost $50 \%$ of all activities and were the most common PA types (mean energy expenditure: $105 \mathrm{MET}-\mathrm{h} /$ week). Restriction of PA in pregnancy was reported by over $60 \%$ of the women, most often due to concerns over proper foetal development. Over $85 \%$ of prenatal care providers either did not address the issue of PA with the future mothers at all, or recommended PA restriction.

Conclusions. Sedentary and light-intensity PA are the two predominant types of physical activity in the third trimester. The most energy-consuming tasks involve household and caregiving activities. Restriction of activity was reported by the majority of the respondents. Prenatal care providers either did not address the matter of PA in pregnancy or recommended PA restriction.
\end{abstract}

\section{Key words}

pregnancy, physical activity, exercise, prenatal care

\section{INTRODUCTION}

Regular physical activity (PA) during pregnancy has been known to reduce the risk for adverse pregnancy outcomes and is indicated in most cases. Physically active women are less likely to develop pregnancy-induced hypertension or preeclampsia [1]. Physical activity also helps with weight management, reduces the risk for gestational diabetes in obese women, and promotes emotional well-being $[2,3]$. Infants born to physically active mothers are at lower risk for macrosomia, as well as obesity and metabolic diseases in the future $[4,5]$. Physical exercises performed since the very beginning of pregnancy have a positive effect on the development of the placenta, its surface area, and the number of its blood vessels [6]. Furthermore, the placentas

Address for correspondence: Cezary Wojtyła, European Observatory of Health Inequalities, State University of Applied Sciences, Kaszubska 13, 62-800 Kalisz, Poland

E-mail: czwo@op.pl

Received: 11.03.2019; accepted: 05.07.2019; first published: 22.08.2019 of physically active mothers have a higher number of villi. These factors determine adequate placental blood perfusion and transport capacity, both of which condition proper foetal development $[7,8]$.

However, physical activity in pregnancy must be exercised with caution and adequate intensity, in order to maintain its positive effect on the development of the placenta. Both, excessive PA as well as lack of it are detrimental to the developing foetus. High-intensity PA may be associated with the possibility of foetal oxygen deficiency, which depends on maternal fitness. Women who were physically active on a regular basis before pregnancy were able to exercise with high-intensity without the risk for foetal hypoxia [9]. This is of vital importance as cessation of PA results in reduced cardiac output, which additionally decreases the blood flow to the placenta and might intensify the hypoxic effect caused by high-intensity PA [9]. Furthermore, increased PA may also negatively affect the blood flow to the uterus. Exercises with submaximal intensity performed in the third trimester may gradually increase the systolic-diastolic ratio in the 
uterine artery, which is not reflected by the same indices in the cord blood [10].

Pregnancy constitutes a specific time in the life of a woman, when health becomes the priority. Modification of life habits and plans ensures optimal conditions for foetal development. However, these changes are not always compliant with expert recommendations. Lack of sufficient knowledge, together with lack of support from the healthcare professionals, are the reasons why future mothers often rely on their personal beliefs or unverified sources. Restriction of physical activity is the most visible model of behaviour already at the very beginning of pregnancy $[11,12]$ and the tendency increases with progressing pregnancy $[13,14]$. PA levels decrease, both for moderate- and high-intensity activity, while the number of women who lead a sedentary style of life continues to grow. According to a Danish study, that rate increases from $6 \%$ to $29 \%$ in the event of pregnancy [15]. Reports from Brazil are even more alarming, with only $4.7 \%$ of pregnant women declaring PA during their leisure time throughout the entire course of pregnancy. PA levels during that time decreased by $2 \%$ at the beginning of pregnancy and continued to drop with every trimester [16]. Santos et al., in their study on a group of Portuguese women, also confirmed that trend [14]. In contrast, studies from the UK indicate that $48.8 \%$ of pregnant women at 18 weeks of gestation engaged in physical activity of over three hours a week, which is comparable to their data from 32 weeks of gestation [17].

The exact relationship between physical activity in pregnancy and pregnancy outcomes remains the subject of much debate $[18,19]$. However, the type of activity seems to play the key role in improving pregnancy outcomes. The American College of Obstetricians and Gynecologists (ACOG) recommends at least 150 minutes per week of moderateintensity aerobic activity (i.e., equivalent to brisk walking), distributed throughout the week and adjusted to medical recommendations [3]. Vigorous-intensity aerobic activity is also recommended, but in a group of highly active women before their pregnancy. That kind of PA is recommended before, during and after pregnancy, and also in the third trimester of pregnancy [3]. Despite the positive effect of PA on proper foetal development, future mothers do not always comply with these recommendations [20]. According to the Pol-PrAMS study, women not only do not comply with the expert recommendations regarding PA during pregnancy, but also frequently engage in risky behaviours. As many as 1 in 10 women admit to smoking in pregnancy and some to alcohol consumption $[21,22,23]$.

\section{OBJECTIVES}

The aims of the study were to establish PA patterns for pregnant women in the third trimester, and to determine the attitudes of prenatal care providers to PA in pregnancy.

\section{MATERIALS AND METHOD}

The analysis was conducted using survey questionnaires from the so-called Polish Pregnancy-related Assessment Monitoring System (Pol-PrAMS) programme. The questionnaire was modelled on its American equivalent from the Pregnancy Risk Assessment Monitoring Survey (PRAMS) programme [24]. This population-based study was conducted between February - March 2017 in all public hospitals in Poland. Consent from the head of the hospital was obtained in each case. A group of Polish women and their newborns were investigated in all public hospitals in Poland during postpartum hospitalization (first days after delivery). Thus, all women who were hospitalized postpartum on the designated days of the study were deemed eligible for the study. The Ethics Committee of The Institute of Rural Health in Lublin, Poland, approved the study (Ref. No. 03/2011). Informed consent was verbally obtained from all women and approved by the Ethics Committee. Participation was anonymous and voluntary, and the surveys completed by the women after consent. Thus, each completed questionnaire was a documentation of consent to the study. Overall, 3,451 parturients and their newborns hospitalized in the obstetric wards of hospitals in Poland were investigated.

The Pregnancy Physical Activity Questionnaire (PPAQ) was used to estimate Physical Activity of pregnant women in third trimester of pregnancy. This part of the survey questionnaire was completed by 2,744 postpartum women. Detailed methodology of the Pol-PrAMS study has been presented in a separate study [25]. The questions were related to PA during pregnancy which was connected with everyday activities: household/caregiving activities (questions number 4-10 and 15-19), occupational activities (questions 32-36), as well as sport/exercise during leisure time (questions 2331). The respondents completed the questionnaire without assistance and selected the answer which most adequately represented time allotted for each of the investigated activities. In light of the fact that the questionnaires were completed by women during postpartum hospitalization, the questions were related to their third-trimester activities. Time allotted to each daily activity from the questionnaire was then multiplied by its intensity. The intensity and the time predictor for each question were determined using the PPAQ instruction [26], based on the widely-used Compendium of Physical Activities [27], thus obtaining the energy expenditure measured in Metabolic Equivalent of Task (MET). The result was then multiplied by the number of days in the week to measure the energy expenditure per hour per week (MET-h-week). Total PA of the pregnant women, classified by type and intensity, was analyzed. The collected data were presented using median and values of the $25^{\text {th }}$ and $75^{\text {th }}$ percentile. Therefore, the obtained results reflect the third-trimester (late pregnancy) PA of the subjects. The survey used in the Pol-PrAMS study also included questions about attitudes to PA in pregnancy of both the prenatal care provider and the patient. The respondents were asked the following question: 'Did you restrict your physical activity due to pregnancy?'. The following descriptive answers were expected: 'Yes, slightly/significantly' or 'No', depending on their subjective evaluation. The women were also asked about the reasons for PA restriction, using the following suggestions:

- concern over proper foetal development;

- lack of knowledge about the safety of sport activity during pregnancy;

- financial; lack of acceptance from the family/environment; recommendations from the prenatal care provider. 
The recommendations of the prenatal care provider regarding PA during pregnancy were also investigated.

The subjects were supposed to select one of the following answers:

- no mention of PA during pregnancy;

- restriction due to medical reasons;

- restriction due to other reasons;

- maintain habitual physical activity;

- increase physical activity.

Data were analyzed using IBM SPSS Statistics version 24.0 (IBM Corp., Armonk, NY, USA). The collected data, depending on variable type, were organized including sample size, percentages in the subgroups, or descriptive analysis Tables including sample size, mean and standard deviation, median and values of the $25^{\text {th }}$ and $75^{\text {th }}$ percentile. The Chi square test was used to analyze the dependency between categorical variables. The $\mathrm{p}$-value of $<0.05$ for a two-tailed test was considered as statistically significant.

\section{RESULTS}

Characteristics of the study population are presented in Table 1. Nearly half of the women participating in the PolPrAMS study were between 21-30-years-old. The weight of slightly over $65 \%$ of the women ranged from $51-70 \mathrm{~kg}$. The height of almost $80 \%$ was $161-180 \mathrm{~cm}$. The largest group $(66.4 \%)$ comprised women with normal body mass. There were respectively $7.6 \%$ and $8 \%$ of women with various degrees of obesity and underweight. Almost half of the women did mental work and had secondary education. Almost $60 \%$ of the women lived in urban areas, and slightly over $41 \%$ in rural areas. The most common way of delivery was vaginal birth $(58 \%)$, whereas almost $41 \%$ gave birth by cesarean section. There were statistically significant differences regarding the total physical activity in the group of the following variables: working status, place of residence, education.

Total PA in the third trimester, classified according to type and intensity, is presented in Table 2. Physical activity in the third trimester was analyzed among women who completed PPAQ (2,744 women). Median of the total energy expenditure: 196.9 MET-h/week. Sedentary or light physical activity accounted for almost $75 \%$ of the total PA, and only $25.8 \%$ for moderate-intensity PA. In terms of percentages, vigorous-intensity $\mathrm{PA}$ remained insignificant.

Of all the PA types, household and caregiving activities accounted for almost half of the energy expenditure, with only 3\% of the total PA for sport activity. Changes in PA during pregnancy, their reasons and recommendations of the prenatal care providers concerning PA in pregnancy are presented in Table 3. Almost $40 \%$ of the respondents declared no restriction of activity due to pregnancy, while $61.5 \%$ reported some restriction of activity, compared to pre-pregnancy PA, with $37 \%$ declaring significant restriction of activity. Concern over proper foetal development was the main cause for PA restriction $-63.8 \%$ of respondents. Almost $35 \%$ of the women declared that the restriction of physical activity was recommended by their prenatal care provider. Also, almost 7\% were not aware that sports activity was safe in pregnancy. As many as $58.5 \%$ of the prenatal care providers did not address the issue of PA in pregnancy at all. Of the remainder the majority recommended restriction
Table 1. Characteristics of the study population

\begin{tabular}{|c|c|c|c|}
\hline & No. & $\%$ & $\begin{array}{l}P \text { - value } \\
\text { (total PA) }\end{array}$ \\
\hline Age & & & $>0.05$ \\
\hline Under 20 & 130 & 3.8 & \\
\hline $21-30$ & 1,703 & 49.9 & \\
\hline $31-40$ & 1,507 & 44.1 & \\
\hline Over 40 & 73 & 2.1 & \\
\hline Weight before pregnancy & & & $>0.05$ \\
\hline$<=50 \mathrm{~kg}$ & 375 & 11.29 & \\
\hline $51-70 \mathrm{~kg}$ & 2,202 & 65.71 & \\
\hline $71-90 \mathrm{~kg}$ & 651 & 19.43 & \\
\hline$>90 \mathrm{~kg}$ & 123 & 3.68 & \\
\hline Height & & & $>0.05$ \\
\hline$<=160 \mathrm{~cm}$ & 692 & 20.7 & \\
\hline $161-180 \mathrm{~cm}$ & 2,633 & 78.74 & \\
\hline$>180 \mathrm{~cm}$ & 19 & 0.57 & \\
\hline BMI & & & $>0.05$ \\
\hline Below 18.5 (underweight) & 266 & 8.0 & \\
\hline $18.5-24.9$ (normal) & 2,207 & 66.4 & \\
\hline 25-29.9 (pre-obesity) & 599 & 18.0 & \\
\hline 30-34.9 (obsesity class I) & 183 & 5.5 & \\
\hline 35-39.9 (obesity class II) & 54 & 1.6 & \\
\hline$>=40$ (obesity class III) & 15 & 0.5 & \\
\hline Working status & & & $<0.05$ \\
\hline Mental work & 1,605 & 47.6 & \\
\hline Physical work & 910 & 27.0 & \\
\hline Unemployed & 716 & 21.2 & \\
\hline Studying & 143 & 4.2 & \\
\hline Place of residence & & & $<0.05$ \\
\hline City $>500,000$ residents & 341 & 10.2 & \\
\hline City $100,000-499,999$ residents & 463 & 13.9 & \\
\hline City 50,000-99,999 residents & 411 & 12.3 & \\
\hline City $10,000-49,999$ residents & 521 & 15.6 & \\
\hline City $<10,000$ residents & 222 & 6.7 & \\
\hline Rural area & 1,373 & 41.2 & \\
\hline Education & & & $<0.05$ \\
\hline Basic & 71 & 2.1 & \\
\hline Secondary & 1547 & 45.7 & \\
\hline Higher & 1,768 & 52.2 & \\
\hline Method of delivery & & & $>0.05$ \\
\hline Vaginal & 1,879 & 58.01 & \\
\hline Cesarean section & 1,324 & 40.88 & \\
\hline Assisted delivery (vacuum/forceps) & 36 & 1.11 & \\
\hline
\end{tabular}

of activity due to various reasons. As many as $14.2 \%$ of the physicians advised maintaining habitual physical activity during pregnancy, and only $0.9 \%$ recommended increased PA. 
Table 2. Total physical activity, in the third trimester, classified according to type and intensity

\begin{tabular}{|c|c|c|c|c|c|c|}
\hline Variable & Mean & Standard deviation & Median & $25^{\text {th }}$ percentile & $75^{\text {th }}$ percentile & $\%$ of total activity \\
\hline Total activity & 214.9 & 118.91 & 196.9 & 137.1 & 268.9 & 100.0 \\
\hline \multicolumn{7}{|l|}{ Intensity } \\
\hline Sedentary & 67.0 & 41.76 & 61.4 & 35.2 & 92.8 & 31.2 \\
\hline Light & 93.3 & 53.91 & 85.6 & 54.3 & 123.6 & 43.4 \\
\hline Moderate & 55.3 & 65.64 & 34.3 & 10.1 & 75.9 & 25.8 \\
\hline \multicolumn{7}{|l|}{ Type } \\
\hline Household/Caregiving & 105.0 & 80.92 & 82.8 & 48.3 & 141.7 & 48.9 \\
\hline Occupational activity & 36.1 & 59.26 & 3.9 & 0.0 & 67.2 & 16.8 \\
\hline Sports/Exercise & 7.2 & 8.56 & 4.8 & 2.3 & 9.6 & 3.3 \\
\hline
\end{tabular}

Table 3. Changes in physical activity during pregnancy, reasons, and recommendations of prenatal care provider

\begin{tabular}{lccc}
\hline & No. & $\%$ \\
\hline Did you restrict your physical activity due to pregnancy? & & \\
\hline No & 1,061 & 38.5 \\
\hline Yes, slightly & 675 & 24.5 \\
\hline Yes, significantly & 1,018 & 37.0 \\
\hline $\begin{array}{l}\text { Reasons for restriction/ cessation of physical activity } \\
\text { during pregnancy }\end{array}$ & & \\
\hline Concern over proper foetal development & 1,159 & 63.8 \\
\hline Lack of knowledge about the safety of sport activity during & 124 & 6.8 \\
\hline pregnancy & 92 & 5.1 \\
\hline Financial & 44 & 2.4 \\
\hline Lack of acceptance from family/environment & 623 & 34.3 \\
\hline Recommendations from prenatal care provider & & \\
\hline Prenatal care provider's recommendations for physical & & 24 & 0.9 \\
\hline $\begin{array}{l}\text { activity during pregnancy } \\
\text { No mention of PA during pregnancy }\end{array}$ & 1,605 & 58.5 \\
\hline Restriction due to medical reasons & 444 & 16.2 \\
\hline Restriction due to other reasons & 283 & 10.3 \\
\hline Maintain habitual physical activity & 389 & 14.2 \\
\hline \begin{tabular}{l} 
Increase physical activity \\
\hline
\end{tabular} & 24 \\
\hline
\end{tabular}

\section{DISCUSSION}

From the questionnaires for evaluation of PA among pregnant women $[28,29,30]$, the validated Pregnancy Physical Activity Questionnaire was used due to its accessibility, repeatability, ease of application, small number of questions, and lead time. The PPAQ was only a part of a large survey within the Pol-PrAMS project. PPAQ was designed for pregnant women and includes activities and their combinations which reflect the PA patterns of the future mothers, allowing isolation the following PA types out of the total PA: household and caregiving, occupational, and sports activities. It also allowed determination of the PA intensity (sedentary, light, moderate and vigorous), making it possible to establish a pattern of PA during pregnancy and comparison between various study populations. The current study has shown that sedentary and light-intensity activities constituted a significant part of PA in the third trimester of pregnancy. Household and caregiving activities accounted for the largest part of the daily energy expenditure. Most women reported restriction of physical activity during pregnancy. According to the mothers, healthcare professionals either failed to address the issue of physical activity altogether or recommended PA restriction in pregnancy.

In this study it was found that activity of light-intensity and sedentary activity accounted for the majority of the total energy expenditure among pregnant Polish women. In total, low-intensity PA (i.e. sedentary and low activity) constituted almost three quarters of their total energy expenditure. This is alarming as physical inactivity in pregnancy is a known risk factor for excessive weight gain and pregnancy complications $[3,31,32]$. In other words, moderate-intensity $\mathrm{PA}$, which is recommended by the experts, comprised only $25 \%$ of the energy expenditure. Polish pregnant women did not engage in higher-intensity activities, therefore their PA patterns have changed considerably, compared to the pre-pregnancy period. A study conducted in a group of 4,064 women with the use of International Physical Activity Questionnaire (IPAQ) indicated that moderate-intensity PA accounted for $43.0 \%$ of the total energy expenditure, while high- and low-intensity PA for $31.35 \%$ and $24.75 \%$, respectively [33].

In the current study it was found that household and caregiving activities were the most common types of PA among Polish pregnant women, which is consistent with the findings of Chandonnet et al., in their study of French women [34], and Schmidt et al., in a group of German women [35]. Nevertheless, these women more often engaged in sports activities. Results of the current study were also similar to the findings of Santos et al., who reported a similar distribution of PA intensity among Portuguese women in the third trimester of pregnancy [14]. However, moderate-intensity activities resulted in a slightly higher energy expenditure in that group of women. Also, Portuguese women were more engaged in occupational activities. Cohen et al., observed yet another pattern of PA. Their group of Canadian women was most likely to engage in sedentary, and less likely in light-intensity activities [36]. Their rates of moderate-intensity PA were similar to the current findings. In the group of Canadian women, the highest energy expenditure was connected with transport-related activities. Compared to their Polish peers, Canadian women were less engaged in household and caregiving activities, but more active as far as occupational activity was concerned. All the above-mentioned studies used PPAQ.

A comparison of the above-mentioned results demonstrated that pregnant women in their late pregnancy mainly engaged 
in low-intensity activities. However, the distribution of physical activity revealed differences in terms of PA types. Polish, German and French pregnant women were more likely to engage in domestic activities, while Canadian and Portuguese groups in occupational activities. The differences were most probably due to the fact that most Polish pregnant women receive a medical certification (an official document for notification and justification of an absence) from their prenatal care providers. In the current study it was found that only one out of three pregnant women did not receive a sick-leave certification. A similar number of women received the document already in the first trimester of pregnancy. Since the beginning of the second and third trimester, $18.0 \%$ and $18.8 \%$ of the women, respectively, had taken sick leave (data not shown), compared to $80 \%$ of Portuguese women who continued to work throughout the entire course of pregnancy [14].

The attitudes of prenatal care providers to PA during pregnancy are inconsistent. According to the abovementioned sources, approximately $30 \%$ of did not mention the subject of PA during pregnancy to their patients, while in the current study that percentage reached almost $60 \%$, including $27 \%$ who actually advised PA restriction in pregnancy. As a result, over $60 \%$ of pregnant Polish women restricted their PA during pregnancy, with $37 \%$ reporting significant restriction of PA. The main reasons included concerns over proper foetal development or compliance with recommendations of the prenatal care provider. Importantly, inhabitants of rural areas restricted their PA during pregnancy significantly more often, compared to their peers from urban areas. According to earlier studies by the authors of the current study, the mean energy expenditure of urban dwellers was $10 \mathrm{MET}-\mathrm{h} /$ week higher than rural dwellers [37].

The presented study was not without limitations. PPAQ is a self-report tool, which might overestimate the time allocated to various activities, thus resulting in misclassification of the subjects. The study surveyed recall information from participants which might further increase the bias. The data about the attitudes of prenatal care providers to PA in pregnancy were obtained using maternal self-reports and reflect the maternal perceptions of those attitudes, rather than the actual attitudes on the subject. It is important to bear in mind that PPAQ has been validated for pregnant women and used in many other studies, with the same methodology, and only those studies were used for comparison.

This study was conducted in all public hospitals in Poland and all women who were hospitalized on the designated days of the study were deemed eligible for the study. Thus, its population-based character allowed to avoidance of a selection bias. The study included the entire population of women, including those who for medical reasons, limited their physical activity, but were nevertheless included in comparisons between other studies due to their similar methodology.

\section{CONCLUSIONS}

Sedentary and light-intensity activities constituted a significant part of PA among women in the third trimester of pregnancy, with only $25 \%$ of total PA devoted to moderate-intensity activities. Household and caregiving activities accounted for the largest part of daily energy expenditure. Most women reported restriction of activity, mainly due to concern over proper foetal development or due to recommendations of the prenatal care provider. As far as physical activity during pregnancy is concerned, healthcare professionals either failed to address these issues or recommended restriction of PA during pregnancy. It therefore seems prudent to conduct workshops for healthcare professionals to further educate them, as they clearly underestimate the need for physical activity in pregnancy.

\section{REFERENCES}

1. Aune D, Saugstad OD, Henriksen T, Tonstad S. Physical activity and the risk of preeclampsia: a systematic review and metaanalysis. Epidemiology. 2014; 25(3):331-343. doi: 10.1097/ EDE.0000000000000036

2. Aune D, Sen A, Henriksen T, Saugstad OD, Tonstad S. Physical activity and the risk of gestational diabetes mellitus: a systematic review and dose-response meta-analysis of epidemiological studies. Eur J Epidemiol. 2016; 31(10): 967-997.

3. ACOG Committee Opinion No. 650: Physical Activity and Exercise During Pregnancy and the Postpartum Period. Obstet Gynecol. 2015; 126(6): e135-42. doi: 10.1097/AOG.0000000000001214

4. Currie LM, Woolcott CG, Fell DB, Armson BA, Dodds L. The association between physical activity and maternal and neonatal outcomes: a prospective cohort. Matern Child Health J. 2014; 18(8): 1823-30. doi: 10.1007/s10995-013-1426-3

5. Wang Y, Gao E, Wu J, Zhou J, Yang Q, Walker MC, et al. Fetal macrosomia and adolescence obesity: results from a longitudinal cohort study. Int J Obes (Lond). 2009; 33(8): 923-8. doi: 10.1038/ijo.2009.131

6. Bell RJ, Palma SM, Lumley JM. The effect of vigorous exercise during pregnancy on birth-weight. Aust N Z J Obstet Gynaecol. 1995; 35(1): 46-51.

7. Clapp JF 3rd. The effects of maternal exercise on fetal oxygenation and feto-placental growth. Eur J Obstet Gynecol Reprod Biol. 2003; 110 Suppl 1: S80-5.

8. Clapp JF 3rd, Kim H, Burciu B, Lopez B. Beginning regular exercise in early pregnancy: effect on fetoplacental growth. Am J Obstet Gynecol, 2000; 183: 1484-1488.

9. Webb KA, Wolfe LA, McGrath MJ. Effects of acute and chronic maternal exercise on fetal heart rate. J Appl Physiol (1985). 1994; 77(5): 2207-13.

10. Erkkola RU, Pirhonen JP, Kivijärvi AK. Flow velocity waveforms in uterine and umbilical arteries during submaximal bicycle exercise in normal pregnancy. Obstet Gynecol. 1992; 79(4): 611-5.

11. Clapp JF. Effects of Diet and Exercise on Insulin Resistance during Pregnancy. Metab Syndr Relat Disord. 2006; 4(2): 84-90. doi: 10.1089/ met.2006.4.84

12. Wojtyła A, Kapka-Skrzypczak L, Biliński P, Paprzycki P. Physical activity among women at reproductive age and during pregnancy (Youth Behavioural Polish Survey - YBPS and Pregnancy-related Assessment Monitoring Survay - PrAMS) - epidemiological population studies in Poland during the period 2010-2011. Ann Agric Environ Med. 2011; 18(2): 365-74.

13. Borodulin K, Evenson KR, Herring AH. Physical activity patterns during pregnancy through postpartum. BMC Womens Health. 2009; 9: 32. doi: 10.1186/1472-6874-9-32

14. Santos PC, Abreu S, Moreira C, Santos R, Ferreira M, Alves O, et al. Physical Activity Patterns During Pregnancy in a Sample of Portuguese Women: A Longitudinal Prospective Study. Iran Red Crescent Med J. 2016; 18(3): e22455. doi: 10.5812/ircmj.22455

15. Hegaard HK, Damm P, Hedegaard M, Henriksen TB, Ottesen B, Dykes $\mathrm{AK}$, et al. Sports and leisure time physical activity during pregnancy in nulliparous women. Matern Child Health J. 2011; 15(6): 806-13. doi: 10.1007/s10995-010-0647-y

16. Domingues MR, Barros AJ. Leisure-time physical activity during pregnancy in the 2004 Pelotas Birth Cohort Study. Rev Saude Publica. 2007; 41(2): 173-80. Erratum in: Rev Saude Publica. 2007 Jun; 41(3): 493.

17. Liu J, Blair SN, Teng Y, Ness AR, Lawlor DA, Riddoch C. Physical activity during pregnancy in a prospective cohort of British women: results from the Avon longitudinal study of parents and children. Eur J Epidemiol. 2011; 26(3): 237-47. doi: 10.1007/s10654-010-9538-1.

18. Juhl M, Olsen J, Andersen PK, Nøhr EA, Andersen AM. Physical exercise during pregnancy and fetal growth measures: a study within 
the Danish National Birth Cohort. Am J Obstet Gynecol. 2010; 202(1): 63.e1-8. doi: 10.1016/j.ajog.2009.07.033

19. Misra DP, Strobino DM, Stashinko EE, Nagey DA, Nanda J. Effects of physical activity on preterm birth. Am J Epidemiol. 1998; 147(7): 628-35.

20. Lynch KE, Landsbaugh JR, Whitcomb BW, Pekow P, Markenson G, Chasan-Taber L. Physical activity of pregnant Hispanic women. Am J Prev Med. 2012; 43(4): 434-9.

21. Wojtyła C, Wojtyła-Buciora P. Cigarette smoking among pregnant women in Poland. J Health Inequal 2017; 3(1): 47-5. doi: https://doi. org/10.5114/jhi.2017.69165

22. Wojtyła C, Wojtyła A. Alcohol consumption by pregnant women in Poland. J Health Inequal. 2017; 3: 51-57. doi: https://doi.org/10.5114/ jhi.2017.69166

23. Stelmach M, Janik-Koncewicz K, Herbeć A, Wijatkowska K, Wojtyła A, Zatoński WA. Give it up! - a new mobile app and campaign supporting women to quit smoking in Poland - project rationale and app description. J Health Inequal. 2018; 4(1): 23-26 doi: https://doi. org/10.5114/jhi.2018.77644

24. CDC. Pregnancy Risk Assessment Monitoring System. https://www. cdc.gov/prams/ Accessed October 29, 2018.

25. Wojtyla C, Wojtyla-Buciora P. Polish Pregnancy-related Assessment Monitoring System (Pol-PrAMS): research on lifestyle health behaviours of Polish women during gestation - study design. J Health Inequal. 2016; 2: 185-191.

26. Pregnancy Physical Activity Questionnaire. Instruction. http://dapatoolkit.mrc.ac.uk/pdf/pa/PPAQ_instructions_1.pdf Accessed April 20,2018

27. Ainsworth BE, Haskell WL, Whitt MC, Irwin ML, Swartz AM, Strath SJ, et al. Compendium of physical activities: an update of activity codes and MET intensities. Med Sci Sports Exerc. 2000; 32(9 Suppl): S498-504.

28. Chasan-Taber L, Schmidt MD, Roberts DE, Hosmer D, Markenson G, Freedson PS. Development and validation of a Pregnancy Physical
Activity Questionnaire. Med Sci Sports Exerc. 2004 Oct; 36(10): 175060. Erratum in: Med Sci Sports Exerc. 2011; 43(1): 195.

29. Harrison CL, Thompson RG, Teede HJ, Lombard CB. Measuring physical activity during pregnancy. Int J Behav Nutr Phys Act. 2011; 8: 19. doi: $10.1186 / 1479-5868-8-19$

30. Schmidt MD, Freedson PS, Pekow P, Roberts D, Sternfeld B, ChasanTaber L. Validation of the Kaiser Physical Activity Survey in pregnant women. Med Sci Sports Exerc. 2006; 38(1): 42-50.

31. American College of Obstetricians and Gynecologists. ACOG Committee opinion. 549: obesity in pregnancy. Obstet Gynecol. 2013; 121: 213-217.

32. Artal R. The role of exercise in reducing the risks of gestational diabetes mellitus in obese women. Best Pract Res Clin Obstet Gynaecol. 2015; 29(1): 123-32. doi: 10.1016/j.bpobgyn.2014.05.013

33. Bergier J, Kapka-Skrzypczak L, Biliński P, Paprzycki P, Wojtyła A. Physical activity of Polish adolescents and young adults according to IPAQ: a population based study. Ann Agric Environ Med. 2012; 19(1): 109-15

34. Chandonnet N, Saey D, Alméras N, Marc I. French Pregnancy Physical Activity Questionnaire compared with an accelerometer cut point to classify physical activity among pregnant obese women. PLoS One. 2012; 7(6): e38818. doi: 10.1371/journal.pone.0038818

35. Schmidt T, Heilmann T, Savelsberg L, Maass N, Weisser B, EckmannScholz C. Physical Exercise During Pregnancy - How Active Are Pregnant Women in Germany and How Well Informed? Geburtshilfe Frauenheilkd. 2017; 77(5): 508-15. doi: 10.1055/s-0043-107785

36. Cohen TR, Plourde H, Koski KG. Use of the Pregnancy Physical Activity Questionnaire (PPAQ) to identify behaviours associated with appropriate gestational weight gain during pregnancy. J Phys Act Health. 2013; 10(7): 1000-7.

37. Wojtyła A, Kapka-Skrzypczak L, Paprzycki P, Skrzypczak M, Biliński P. Epidemiological studies in Poland on effect of physical activity of pregnant women on the health of offspring and future generations adaptation of the hypothesis development origin of health and diseases. Ann Agric Environ Med. 2012; 19(2): 315-26. 